\title{
POLÍTICAS LINGUÍSTICAS E ENSINO DE LÍNGUAS MINORITÁRIAS E MAJORITÁRIAS NO BRASIL: O CASO DO POMERANO E DO INGLÊS COMO LÍNGUAS ESTRANGEIRAS
}

\author{
POLÍTICAS LINGÜÍSTICAS Y ENSEÑANZA DE LENGUAS MINORITARIAS Y \\ MAJORITARIAS EN BRASIL: EL CASO DEL POMERANO Y DEL INGLÉS COMO \\ LENGUAS EXTRANJERAS
}

\author{
LANGUAGE POLICIES AND TEACHING OF MINORITY AND MAJORITY \\ LANGUAGES IN BRAZIL: THE CASE OF POMERANIAN AND ENGLISH AS \\ FOREIGN LANGUAGES
}

\author{
Lívia Melina PINHEIRO ${ }^{1}$ \\ Kyria Rebeca FINARDI ${ }^{2}$ \\ Maria Carolina PORCINO ${ }^{3}$
}

RESUMO: O estudo reflete sobre políticas linguísticas e o ensino de línguas majoritárias e minoritárias no Brasil. Para tanto, o estudo investiga as crenças de duas professoras de língua estrangeira que trabalham em escolas públicas de uma comunidade Pomerana do Estado do Espírito Santo. As línguas escolhidas para análise foram o inglês, como língua internacional e majoritária, e o pomerano como língua minoritária e de imigração. Após a revisão das políticas linguísticas para o ensino de línguas estrangeiras no Brasil, o estudo oferece uma análise de crenças de professores de línguas estrangeiras coletadas por meio de questionários realizados com duas professoras, uma de inglês e outra de pomerano, em uma comunidade de imigrantes pomeranos no ES. Os resultados da análise dos questionários sugerem que ambas as professoras acreditam que o tempo em que seus alunos são expostos ao aprendizado dessas línguas não seja suficiente para que todas as habilidades linguísticas sejam devidamente desenvolvidas e que os materiais didáticos e os currículos escolares deveriam ser revistos. Por outro lado, a professora de pomerano acredita que o ensino do pomerano é capaz de melhorar a autoestima de seus alunos em relação à sensação de pertencimento ao seu contexto histórico, em sua comunidade local e familiar. No caso da professora de inglês, esta acredita que seus alunos ainda não percebem a importância do inglês para suas vidas acadêmicas e profisssionais. O estudo conclui que é necessário revisar políticas linguísticas para garantir o ensino de línguas minoritárias e majoritárias, estimulando o multilinguismo no Brasil.

PALAVRAS-CHAVE: Políticas linguísticas. Ensino de línguas majoritárias e minoritárias no Brasil. Pomerano. Inglês.

\footnotetext{
1 Universidade Federal do Espírito Santo (UFES) - Vitória - ES - BR. Mestre em Educação. ORCID <https://orcid.org/0000-0003-2156-4393>. E-mail: liviamelinavereb@gmail.com

${ }^{2}$ Universidade Federal do Espírito Santo (UFES) - Vitória - ES - BR. Departamento de Línguas, Cultura e Educação. ORCID <https://orcid.org/0000-0001-7983-2165>. E-mail: kyria.finardi@gmail.com

${ }^{3}$ Universidade Federal do Espírito Santo (UFES) - Vitória - ES - BR. Mestre em Estudos Linguísticos. ORCID <https://orcid.org/0000-0002-1259-4841>. E-mail: carolina_porcino@hotmail.com
} 
RESUMEN: El estudio refleja sobre políticas lingüísticas y la enseñanza de lenguas mayoritarias y minoritarias en Brasil. Para ello, el estudio investiga las creencias de dos profesoras de lengua extranjera que trabajan en escuelas públicas de una comunidad Pomerana del Estado de Espírito Santo. Las lenguas elegidas para el análisis fueron el inglés, como lengua internacional y mayoritaria, y el pomerano como lengua minoritaria y de inmigración. Después de la revisión de las políticas lingüísticas para la enseñanza de lenguas extranjeras en Brasil, el estudio ofrece un análisis de creencias de profesores de lenguas extranjeras recogidas por medio de cuestionarios realizados con dos profesoras, una de inglés y otra de pomerano, en una comunidad de inmigrantes pomeranos en el ES. Los resultados del análisis de los cuestionarios sugieren que ambas profesoras creen que el tiempo en que sus alumnos están expuestos al aprendizaje de esas lenguas no es suficiente para que todas las habilidades lingüísticas sean debidamente desarrolladas y que los materiales didácticos y los currículos escolares deberían ser revisados. Por otro lado, la profesora de pomerano cree que la enseñanza del pomerano es capaz de mejorar la autoestima de sus alumnos en relación a la sensación de pertenencia a su contexto histórico, en su comunidad local y familiar. En el caso de la profesora de inglés, ésta cree que sus alumnos aún no perciben la importancia del inglés para sus vidas académicas y profesionales. El estudio concluye que es necesario revisar políticas lingüísticas para garantizar la enseñanza de lenguas minoritarias y mayoritarias, estimulando el multilingüismo en Brasil.

PALABRAS CLAVE: Políticas lingüísticas. Enseñanza de lenguas mayoritarias y minoritarias en Brasil. Pomerano. Inglés.

ABSTRACT: The study reflects on language policies and the teaching of majority and minority languages in Brazil. With that aim, the study investigates the beliefs of two foreign-language teachers working in public schools in a Pomeranian community in the State of Espirito Santo. The languages chosen for analysis were English as an international and majority language and Pomeranian as a minority and immigration language. After reviewing the language policies for teaching foreign languages in Brazil, the study offers an analysis of the beliefs of foreign language teachers collected through questionnaires with two teachers, one who teaches English and another who teaches Pomeranian, in a community of Pomeranian immigrants in the state of ES. The results of the analysis suggest that both teachers believe that there is not enough time to develop all language skills properly, and that teaching materials and school curricula should be reviewed. On the other hand, the Pomeranian teacher believes that the teaching of Pomeranian is capable of improving the self-esteem of students in relation to their sense of belonging to a historical context, and local and family community. In the case of the English teacher, she believes that her students still do not realize the importance of English for their academic and professional lives. The study concludes that language policies should be reviewed so as to guarantee the teaching of minority and majority languages, stimulating multilingualism in Brazil.

KEYWORDS: Language policies. Majority and minority language teaching in Brazil. Pomeranian. English. 


\section{Introdução}

O Brasil de hoje, ainda é visto por muitos (FINARDI, 2016), como país monolíngue, “dominado pelo português em toda a sua extensão" (MARTINY; BORSTEL, 2012, p. 5) ainda possui uma imagem distorcida de seu panorama linguístico (FERRAZ, 2007). Tendo em vista o papel do inglês, por um lado, e a necessidade de preservar o multilinguismo existente no Brasil, por outro, Finardi (2017) sugere que o inglês seja ensinado como língua internacional (FINARDI, 2014) enquanto outras línguas estrangeiras como espanhol, francês e italiano, sejam incluídas no currículo da educação básica por meio da abordagem de intercompreensão. A sugestão de Finardi (2017) para a preservação das línguas estrangeiras no currículo da educação básica não garante, entretanto, o ensino de línguas de herança ou de imigração como é o caso do pomerano.

Um dos motivos da importância da preservação das línguas minoritárias é muito bem explicado na justificativa, feita pelo vereador Altamiro Antônio Kretzer, da lei de cooficialização da língua hunsruckisch no Município de Antônio Carlos:

As línguas são artefatos históricos, construídos coletivamente, ao longo de centenas ou milhares de anos. É através das línguas que as sociedades humanas, definidas como 'comunidades linguísticas', produzem a maior parte do conhecimento de que dispõe e é através da língua que são construídos os sistemas simbólicos de segunda ordem, como a escrita, as matemáticas, e que permitem a ação humana sobre a natureza e sobre os outros homens (MORELLO, 2015, p. 71).

Além disso, o vereador afirma que as línguas constituem importantes componentes da cultura imaterial o que enfatiza a importância de oportunizar aos falantes de cada língua possibilidades de preservá-las. Dada a importância de fornecer condições aos falantes das mais variadas línguas encontradas em território nacional, este trabalho analisa as políticas linguísticas atuais sobre a cooficialização das línguas minoritárias e também as mais recentes tomadas de decisões sobre o ensino de línguas nas escolas do Brasil, sabendo que até 2017 as políticas linguísticas concretizadas na Lei de Diretrizes e Bases da Educação (LDB) garantiam o ensino de pelo menos uma língua estrangeira, a partir da $6^{\mathrm{a}}$ série. A escolha da língua a ser ensinada recaía na comunidade escolar. Entretanto, a reforma educacional que transformou a Medida Provisória n $^{\circ} 746 / 2016$ na Lei no 13.415 tornou o ensino de inglês obrigatório, sendo o ensino de outras línguas estrangeiras opcional. Essa reforma ameaça a já difícil situação do ensino de outras línguas estrangeiras e de imigração no Brasil. 


\section{O panorama linguístico do Brasil}

Desde sua colonização, o Brasil enfrenta decisões políticas no que concerne às línguas faladas em seu território, visto que os portugueses encontraram uma terra de grandes riquezas, com muitos povos e línguas. A dominação do território, no caso do Brasil, que passa a ser uma colônia portuguesa, se deu também com a imposição da língua do dominador, o português. Outro fator que afetou o multilinguismo ${ }^{4}$ e plurilinguismo ${ }^{2}$ brasileiro foi a vinda de africanos, trazidos como escravos e posteriormente a vinda de imigrantes europeus em busca de uma vida melhor e/ou fugindo das guerras mundiais. Segundo Kuster (2015) esse processo de coibição das línguas pelo Estado Português e pelo Estado Brasileiro foram responsáveis pelo apagamento de muitas línguas e os que sobreviveram foram obrigados a aprender o português, sendo muitas vezes proibidos de falar suas línguas nativas.

De forma resumida, todo o processo de multilinguismo brasileiro, desde dominação por Portugal, evidencia as decisões políticas sobre a língua que deveria ser falada, o português, e as línguas que seriam oprimidas, todas as outras. No caso do Brasil de Vargas, uma das crenças era que os imigrantes alemães pudessem provocar motins e como não se sabia a diferença entre os alemães e os pomeranos, tivemos uma perseguição acirrada a muitos desses grupos quando do uso de qualquer outra língua, que não fosse o português.

Tendo em vista as atitudes tomadas contra as línguas faladas no Brasil durante todos esses anos, sentimos a responsabilidade de mudar essa perspectiva. O olhar atual é o de criar políticas linguísticas para evitar que as línguas minoritárias e de imigração, que ainda existem, se percam por não serem oferecidas no ensino público regular. Para isso é preciso entender a definição das línguas majoritárias e minoritárias e suas importâncias. De acordo com Seiffert (2009), para as questões linguísticas, todas as línguas são iguais. O que não pode ser afirmado no âmbito econômico e político. Para uma língua ser chamada de majoritária, Seiffert usa a definição de Ferguson que aponta que a língua precisa ser: falada por pelo menos $25 \%$ da população; por mais de um milhão de pessoas; ser a língua oficial; ser a língua de ensino em $50 \%$ das escolas secundárias do país. Quesitos que o português preenche com facilidade. Por outro lado, nenhuma outra língua no território nacional possui nenhuma dessas capacidades, por tanto, línguas minoritárias que segundo Altenhofen (2013) são as línguas à margem ou ao lado de línguas dominantes (majoritárias).

\footnotetext{
${ }^{4}$ Multilinguismo: a presença de mais de uma língua.

2 Plurilinguismo: o domínio, pelo falante, de mais de uma língua. Definição em: Carta Européia do Plurilinguismo (2009): http://e-ipol.org/wp-content/uploads/2013/04/Carta_Europeia_do_Plurilinguismo.pdf
} 
Segundo Finardi (2016), o Brasil sofre pressão para reconhecer as muitas línguas faladas aqui, ao mesmo tempo em que luta para aprender a língua do vizinho (espanhol) e sofre pressão para aprender a língua internacional, o inglês (FINARDI, 2014). O governo nacional demonstra sua necessidade de fazer parte do mundo globalizado nas políticas linguísticas (vide reforma educacional mencionada anteriormente no texto) e de internacionalização materializadas em programas governamentais como o Ciências sem Fronteiras (CsF), o Inglês sem Fronteiras (IsFInglês) (FINARDI; ORTIZ, 2015; PINHEIRO; FINARDI, 2014; PINHEIRO; FINARDI, 2016) e mais recentemente o Idiomas sem Fronteiras (IsF).

O estado do Espírito Santo recebeu vários tipos de imigrantes europeus de origem germânica, das regiões onde hoje se encontram hoje a Alemanha, a Áustria, a Suíça, a Holanda, Luxemburgo e a Bélgica e com eles vieram todas as línguas oriundas desses povos. O que explica o prevalecimento da língua pomerana, nas comunidades de imigrantes, é a quantidade, numericamente maior, de imigrantes pomeranos em relação aos de outras origens e que, segundo Tressmann (1998) acabou absorvendo os demais grupos germânicos. Ou seja, mesmo que cada grupo usasse sua própria língua, eles acabaram aprendendo a falar o pomerano por esta ser a língua mais usada para a comunicação entre esses grupos, comunicação essa que era necessária para a convivência e o comércio.

Para entendermos o panorama linguístico das comunidades pomeranas no Espírito Santo, utilizaremos os dados coletados por Tressmann (1998) que analisou a comunidade do município de Laranja da Terra. Segundo o autor, as línguas de uso mais expressivas nesse município são o pomerano e o português e cerca de $70 \%$ dessa comunidade é bilíngue nessas duas línguas. Dos entrevistados de Tressmann, $86 \%$ adquiriu o pomerano antes dos sete anos e antes do português. Apenas 21\% aprenderam as duas línguas juntas. Quanto ao português, 57\% aprenderam na escola e não no ambiente familiar. Outra informação relevante é o fato de que as mulheres falam mais o pomerano que os homens, visto que a língua pomerana está mais ligada à interação familiar e que a mulher da zona rural, normalmente, possui como ocupação os afazeres de casa e o cuidado dos filhos, sobrando pouco tempo para interagir na cidade e em português. Já os homens falam mais o português pela necessidade de interação comercial e por irem mais à cidade para negociações de suas produções rurais. Tressmann (1998) define, portanto, que neste sentido o pomerano é um idioma mais rural e o português mais urbano.

Num país com muitos habitantes e poucos recursos para o financiamento da inclusão de várias línguas estrangeiras na educação pública regular, a escolha de qual (quais) língua(s) estrangeira(s) oferecer é um desafio enorme e no caso dessa comunidade investigada neste estudo, o desafio é ainda maior. Sabendo que as decisões sobre quais línguas ensinar também 
variam com o grau de valor que estas línguas possuem no "mercado linguístico" (ALTENHOFEN, 2013, p. 95) e esse valor é definido pelos usuários e suas comunidades, dessa forma a escolha da(s) língua(s) ofertadas deveria ser decidida através da compreensão da importância da língua na comunidade. $O$ que pode se tornar complicado com as atuais mudanças nas políticas linguísticas nacionais que está priorizando a obrigatoriedade da oferta do ensino do inglês.

Finardi e Porcino (2015), com base em dados de Peruzzo (2014) sobre um levantamento de crenças de alunos em uma comunidade onde se fala muito pomerano, descobriram que a maior parte dos alunos entrevistados pensava que a inclusão de inglês era mais importante do que a de pomerano. Fato este que pode ser justificado pelas crenças destes alunos (de que o ensino de inglês é mais importante do que o de pomerano) sendo que Peruzzo (2014), aponta duas possíveis hipóteses para essas crenças: a dos alunos não visualizarem o pomerano como língua estrangeira, visto que para eles essa língua é considerada materna, familiar ou de imigração. Por tanto, os alunos não perceberem a importância de seu ensino na escola, cenário que sempre conheceram como lugar de ensino de português e do inglês. Dessa forma existe também a importância de definição e compreensão da função de cada língua para que esses alunos possam ser capazes de refletirem de forma consciente sobre a importância e o papel que estas três línguas precisam fazer em suas vidas.

Como forma de refletir sobre os dados trazidos por Finardi e Porcino (2015) e Peruzzo (2014), aumentando o escopo por meio da análise das crenças de professores de línguas, este estudo revisou políticas linguísticas e analisou as crenças de duas professoras de líínguas estrangeiras que ministram, respectivamente, o inglês, língua majoritária, e o pomerano, língua minoritária e de imigração, nas escolas públicas de comunidades de imigrantes no estado do Espírito Santo.

\section{Línguas minoritárias, de imigração e majoritárias}

As políticas linguísticas precisam ser feitas sob a luz da conscientização da importância de se "dar ouvidos" (ALTENHOFEN, 2013, p. 96) as línguas minoritárias, uma vez que política linguística plural deve ser feita para que haja respeito, inclusão e preservação de todas as línguas faladas por todos os seus falantes. Oriundo da noção de dar "ouvidos" e não "voz" Altenhofen analisa que todos os grupos linguísticos sempre tiveram vozes o que eles nunca receberam foram ouvidos. Dessa forma, toda e qualquer língua minoritária em território nacional pode passar a receber todos os tipos de incentivos e direitos que lhes cabem. 
Nossas línguas minoritárias podem ser classificadas, a grosso modo, como as línguas indígenas, as línguas dos africanos que vieram como escravos e as línguas dos imigrantes asiáticos e europeus. Das línguas indígenas, várias delas foram extintas durante os anos de colonização do Brasil e as que sobreviveram possuem, desde a Constituição Brasileira de 1988, o direito a uma série de ações voltadas para a revitalização de suas identidades, costumes, línguas, crenças e tradições indígenas (FERRAZ, 2007); o que não acontece com as línguas de imigração, que começaram a serem ouvidas a partir de 2002 com a cooficialização da LIBRAS (NEVES, 2013).

Das línguas minoritárias vivas no país, neste trabalho temos como foco o pomerano em razão de sua importância no Estado do Espírito Santo. Das línguas majoritárias ensinadas no país, sendo o estudo do inglês o foco deste artigo, analisamos as políticas linguísticas criadas pela vontade nacional de promover o acesso dos estudantes, principalmente universitários, ao mundo globalizado através da inclusão social destes alunos por meio do inglês e das novas tecnologias (FINARDI; PREBIANCA; MOMM, 2013; FINARDI; TYLER, 2015).

\section{Políticas linguísticas e o ensino de línguas estrangeiras}

A política linguística pode ser entendida como a intervenção feita ou proposta em uma determinada comunidade, para regulamentar o uso de línguas nesse contexto (RAJAGOPALAN, 2013). Segundo Oliveira (2007, p. 395), "políticas linguísticas são uma faceta das políticas públicas dos países [...]” e são construídas visando o futuro de certa sociedade. Fazer política linguística é pensar em promover um mundo mais justo no que concerne às línguas e seus usos. Para Rajagopalan (2013) política linguística é:

[...] a arte de conduzir as reflexões em torno de línguas específicas, com o intuito de conduzir ações concretas de interesse público relativo à (s) língua (s) que importam para o povo de uma nação, de um estado ou ainda, instâncias transnacionais maiores (p. 21).

Esta visão vai de encontro ao que afirma (PERUZZO, 2014, p.8) sobre o idioma ser entendido como o "maior representante de um país, região ou comunidade" e para criar um mundo mais democrático e mais aberto é preciso entender as línguas como a "ecologia de saberes humanos" (OLIVEIRA, 2007, p. 386). Oliveira (2007) é categórico sobre estarmos em um momento histórico em que língua como direito e língua como recurso orientam grande parte das políticas linguísticas. O autor também afirma que a forte expansão da língua como recurso em relação à internacionalização por fluxo de imigrações e pelo fluxo de informação na internet intensifica a importância dela como veículo de inclusão. 
No que tange a escolha das línguas estrangeiras a serem ensinadas no Brasil, ressaltando que o Brasil é o único país no continente Americano que possui o Português como língua oficial e nacional, Finardi (2016) e Day (2012) afirmam que não são escolhas feitas por acaso e são, na verdade, definidas através de muitas ações de gestão de línguas, prevalecendo a escolha da língua pelo poder econômico e influência que esta oferece e, somente em segundo plano, a questão geográfica e cultural entre os falantes.

Day (2012) ressalta também que é preciso lembrar que de acordo com as diferentes realidades brasileiras, diferentes escolhas são possíveis e não cabe ao Estado definir quais fatores são mais ou menos importantes em cada comunidade apesar da notoriedade dada ao espanhol, pelos acordos com os países do MERCOSUL, e ao inglês, vista como língua franca e internacional (FINARDI, 2014), que segundo Martiny e Borstel (2012) são línguas ensinadas em detrimento das línguas minoritárias nas regiões de imigrantes.

A importância do ensino de línguas estrangeiras no Brasil, em específico do inglês, por seu status de língua internacional, tem provocado ações e mudanças também em relação às línguas minoritárias, percebida pela vontade de aprender e preservá-las pela sua importância histórica e cultural. Day (2012) sugere que o indivíduo atual não quer somente fazer parte do mundo globalizado, mas também quer aprender e manter sua identidade regional ou local reconhecida e é essa necessidade de manter viva sua origem e descendência que tem alavancado ações no campo do ensino de línguas minoritárias como no caso do Pomerano no Espírito Santo.

Outra atitude tomada no campo das políticas linguísticas atuais é a cooficialização de línguas minoritárias. Segundo Oliveira (2013), cooficializar uma língua significa que ela se torna oficial, no entanto esta língua fica ao lado da língua oficial. Para que uma língua seja cooficializada é preciso criar:

Comissão Municipal de Políticas Linguísticas, com representantes de escolas municipais e estaduais, câmara municipal, ensino superior, agricultores, etc. Após a aprovação do documento de regulamentação da lei pela Câmara e/ ou Prefeito Municipal, ficarão previstas as medidas concretas a serem implementadas e os modos de atuação do Estado na política linguística de cada município envolvido (TRESSMANN, 2009, p.1).

No caso do pomerano, sua cooficialização lhe dará o reconhecimento e todos os direitos de uma língua oficial segundo Tressmann (2009) e essa língua passa a ter espaço, consequentemente, em todos os setores públicos e privados, no entanto, várias tomadas de decisão precisam ser feitas e vários ajustes organizacionais, como traduções de documentos públicos tanto quanto intérpretes para atender essa comunidade. Além disso, tomadas de decisão precisam ser feitas no âmbito escolar para definir como o ensino dessa língua será feito. 
Conclui o autor que o poder público passa a ser capaz de incentivar e apoiar o aprendizado e o uso do pomerano em todos os meios de comunicação, tornando possível o bilinguismo nestas regiões.

\section{A cooficialização do pomerano}

O primeiro município a cooficializar o pomerano no Espírito Santo, segundo Morello (2015), foi Santa Maria de Jetibá, conhecido por ter a maior concentração de imigrantes pomeranos e onde Peruzzo (2014) realizou seu estudo. Foi através da promoção de debates e de audiências que essa comunidade conseguiu ser a primeira a realizar um censo linguístico em seu território com o intuito de identificar os falantes e de criar políticas voltadas ao pomerano. Ainda segundo Morello (2015), o pomerano já é cooficializado também nos municípios de Laranja da Terra, Pancas, Vila Pavão e Domingos Martins.

Cabendo a cada município a tarefa de cooficialização de línguas, este trabalho analisou as possíveis diferenças entre as leis estabelecidas em cada município do Espírito Santo onde a cooficialização já se encontra estabelecida, para entender como é feito a cooficialização e o que está previsto na lei para o ensino do pomerano. A lei de cooficialização do pomerano em todos os municípios ratifica o português como idioma oficial da República Federativa do Brasil e o pomerano como língua cooficializada nesses municípios. Em comum também temos a obrigatoriedade da produção de documentos públicos, o atendimento ao público através da língua oficial e da língua cooficializada, ficando claro pelas leis dos municípios, que a discriminação pelo uso da língua cooficializada não será permitido.

Quanto ao ensino e aprendizagem do idioma, temos nos municípios de Santa Maria de Jetibá, Laranja da Terra, Vila Pavão e de Domingos Martins a similaridade quanto ao estímulo dado pela lei para o incentivo e o apoio ao aprendizado da língua cooficial nas escolas e nos meios de comunicação. Porém, não fica claro a introdução do ensino do pomerano nas escolas da Rede Municipal de Ensino destes municípios como fica na lei de Pancas: Lei N 987/2007De 27 de Julho de 2007 que vai de encontro aos Art. 26 e 28 da Lei Federal 9394/96 - Lei das Diretrizes e Bases da Educação. Essa diferença nas leis pode influenciar a diferença em como o pomerano é escolhido e ensinado nas escolas de comunidades pomeranas que é a língua materna de uma grande parcela das crianças dessas comunidades. 


\section{O inglês como língua majoritária}

A importância de classificar o inglês não somente como língua franca, internacional (FINARDI, 2014) e, também, como língua majoritária, é aceitar que a "globalização diminuiu as distâncias entre os povos e acelerou seu contato, muitas vezes por meio do inglês e da internet" (PINHEIRO; FINARDI, 2016, p.2).O que diferencia o inglês das outras línguas estrangeiras é seu estatuto de língua internacional, no sentido de ter ultrapassado as fronteiras dos países que possuem o inglês como língua oficial e ter sido tão difundida a ponto de não somente pertencer a estes países, mas sim a todos os que se apropriam dessa língua por meio do seu uso (FINARDI, 2014).

Finardi, Prebianca e Momm (2013) afirmam que a internet e o conhecimento de inglês ampliam o acesso à informação online assim como Finardi e Tyler (2015) sugerem que o conhecimento de inglês amplia também o acesso à educação online por meio de cursos abertos e dirigidos a um público amplo (Massive Online Open Courses ou MOOCs na abreviação em inglês). Tanto o acesso à informação quanto à educação online pode aumentar a possibilidade de construção de uma cidadania global ainda que para o desenvolvimento de uma cidadania plena a produção de conhecimento também seja importante. Nesse sentido, Finardi e França (2016), em um estudo sobre a produção acadêmica nacional concluem que apesar do Brasil ter a $13^{a}$ maior produção acadêmica mundial, essa produção não alcança o impacto desejado (por meio de citações), em parte, por causa do idioma no qual nossa produção é veiculada (português).

Em relação aos investimentos brasileiros para a promoção do ensino e aprendizado de inglês no ensino superior, Pinheiro e Finardi (2014), ao analisarem os programas Ciência sem Fronteiras (CsF) e Inglês sem Fronteiras (IsF-Inglês), concluíram que para que a internacionalização aconteça de forma eficaz no ensino superior é necessário investir mais na formação docente e no ensino de inglês como língua internacional para todas as áreas do conhecimento, não apenas para as que eram contempladas pela primeira edição do programa CsF. Finardi, Prebianca, Schmitt e Andrade (2014) vão além e sugerem que para que o programa IsF-Inglês faça diferença no ensino de inglês no Brasil o programa deveria se articular com a educação básica e não apenas ser oferecido na educação superior.

O maior desafio brasileiro na atualidade, no que concerne o ensino das línguas estrangeiras, é a inclusão social que, segundo Prebianca, Cardoso e Finardi (2014), se dá pela árdua tarefa de fazer com que as políticas linguísticas e educacionais sejam cumpridas, o que traz dificuldades para o alinhamento do ensino com as necessidades da atual sociedade 
brasileira, ocasionado pelo progresso tecnológico. Os brasileiros precisam e querem aprender inglês (GIMENEZ, 2013) e esse é o motivo pelo qual as políticas linguísticas precisam se alinhar à política de internacionalização, combatendo a lacuna social criada pela desigualdade de oferta de cursos de inglês no setor público e privado, que favorece o setor privado, como afirmam Pinheiro e Finardi (2016) e Finardi (2014).

\section{O ensino do pomerano como língua minoritária e de imigração}

O pomerano é "uma língua de imigração falada em cinco estados do Brasil, tanto pelos adultos como pelos jovens e crianças" (TRESSMANN, 2009, p. 1) e já se faz presente no Espírito Santo há mais de 150 anos, estimando-se que aproximadamente 120 mil pessoas falem essa língua. As comunidades pomeranas no estado do Espírito Santo, em sua grande maioria, localizam-se nos municípios de Domingos Martins, Santa Maria de Jetibá, Colatina, Vila Pavão, Laranja da Terra e Pancas.

A visão do pomerano, todavia, sofre preconceitos, sendo um deles, o de não ser uma língua majoritária, trazendo consequências para o uso e preservação dessa língua. Tressmann (2009) relata que existem pais que escolhem falar com seus filhos em português para que estes não passem as mesmas dificuldades que seus pais passaram para se adaptar na escola, que é, segundo o autor "o lugar da discriminação e da falsa homogeneidade linguística e cultural" (TRESSMANN, 2009, p. 11). O que mostra que a escola e o governo precisam rever como é ensinado o português e a importância dada a vida e a história desses novos alunos, resolvendo a má adequação dos currículos escolares nas comunidades pomeranas visto que em muitos casos, as crianças chegam à escola sem saber falar português.

Um grande marco para o pomerano no Espírito Santo foi a visita do Professor Doutor Gilvan Müller de Oliveira, em 2007, iniciando o processo da cooficialização da língua Pomerana. Pensando na necessidade de preservação e revitalização dessa língua é que foi criado o Programa de Educação Escolar Pomerana (Proepo), em 2005, passando a existir o uso do pomerano em atividades escolares de algumas das escolas destes municípios. Segundo Tressmann (2009), o objetivo do Proepo é valorizar e fortalecer a cultura pomerana em sua modalidade escrita e oral. Ainda segundo Tressmann (2009), a incorporação do Proepo, a edição do Dicionário Pomerano e o Livro-Texto Upm Land "Na Roça" foram fatores que contribuíram fortemente para o fortalecimento da língua pomerana e de seus falantes. 


\section{Crenças de professores de línguas}

Crenças podem ser entendidas como ideias presentes na sociedade e que fazem parte do discurso e das escolhas dos indivíduos. Cabe ressaltar que as atitudes tomadas diariamente por indivíduos, são fruto da junção de crenças e responsabilidades que este indivíduo sente que deve cumprir para que seu papel na sociedade seja estabelecido. Da mesma forma, cada decisão tomada coletiva ou individualmente reflete as crenças que estes grupos ou pessoas abrigam.

Uma vez que quem conduz o ensino na sala de aula é o professor e as decisões tomadas em sala de aula são influenciadas pelas crenças de cada professor. Assim, analisar as crenças dos professores, quanto ao ensino de línguas, é refletir sobre o que este professor acredita ser verdade. No nosso caso específico, as crenças que rondam os professores de línguas estrangeiras podem influenciar positiva ou negativamente o ensino dessas línguas e refletir sobre as crenças é entender o contexto escolar e linguístico do aluno, da escola e do professor, abrindo espaço para eliminar possíveis preconceitos linguísticos.

Em relação a crença e a teoria que estão disponíveis para professores, Finardi (2014) sugere que na ausência de teoria, os professores tomam decisões com base em suas crenças. Segundo Barcelos (2004), é importante que os próprios professores também conheçam e saibam quais são as crenças que envolvem seu trabalho e a vida de seus alunos, visto que as tomadas de decisões em sala de aula se dão através das crenças que circundam a vida social e profissional deste professor.

De acordo com Finardi (2014) as crenças linguísticas são, na maioria das vezes, internalizadas de forma inconsciente e no caso dos professores de línguas, essas crenças podem afetar como e o que eles ensinam. Ainda de acordo com Finardi (2014), mais importante do que o desenvolvimento em si, é desenvolver na direção certa e para isso é preciso que o ensino, a teoria, as crenças e os professores de línguas sejam analisados de forma a entender a realidade visando à melhoria no desenvolvimento profissional de professores, do ensino das línguas e das decisões tomadas pelo governo, sociedade e professores com vistas a melhorar o ensino de línguas como um todo. A fim de refletir sobre essa possibilidade, no que segue descrevemos a metodologia usada para investigar as crenças de dois professores de línguas estrangeiras no ES.

\section{Participantes}

As participantes desta pesquisa são duas professoras de línguas estrangeiras, a primeira de inglês no Instituto Federal do Espírito Santo (IFES) - Campos Centro Serrano em Santa Maria de Jetibá e a segunda, é professora de pomerano em duas escolas públicas municipais de 
ensino fundamental: EMEIEF" Luiz Guilherme Henrique Potratz" e EMEF" em Vila de Jetibá. A escolha das participantes da pesquisa se deu em virtude da conveniência e disposição de ambas. A fim de entender as crenças desses professores em relação à língua que elas ensinam, um questionário foi elaborado para ser usado como guia em entrevistas realizadas individualmente com essas professoras, considerando os papéis do pomerano e do inglês na comunidade onde elas lecionam.

\section{Análise das crenças das professoras de línguas estrangeiras Crenças da professora de inglês}

As primeiras perguntas do questionário são de caráter biográfico e se referem ao nome da professora, há quanto tempo ela trabalha na escola e há quanto tempo leciona essa disciplina. A professora de inglês, doravante chamada de MC para proteger sua identidade, trabalhava no IFES Centro Serrano - Santa Maria de Jetibá há três meses, durante o período de coleta de dados. MC dá aula para alunos do curso técnico integrado do ensino médio com superior de administração e leciona a língua inglesa há mais de oito anos.

MC afirma que sua principal dificuldade tem sido a diferença entre os níveis de proficiência em sala de aula associada à falta de interesse por parte dos alunos por esta língua, uma vez que a primeira língua da maioria de seus alunos é o português. A professora enfatiza para os alunos a importância do aprendizado de inglês como possibilidade de ampliação dos estudos e entrada no mercado de trabalho. Porém, mesmo com seu trabalho diário nesta escola, ela sente que a maioria de seus alunos não acredita ser capaz de aprender inglês e tem a sensação que eles não conseguem entender a importância dessa língua para suas vidas acadêmica e profissional. Por outro lado, MC entende que o tempo curricular para o ensino de inglês, que são duas aulas por semana de 50 minutos cada, não seja suficiente para que seus alunos se tornem competentes no uso dessa língua em todas as suas habilidades, além do fato da quantidade de alunos por sala (40 em média) dificultar a produção oral e compreensão auditiva dos alunos nessa língua.

Quanto ao conteúdo trabalhado em sala de aula, MC segue o cronograma decidido no início do ano letivo, utilizando o livro didático para a apresentação do conteúdo, ainda que ela tente, na medida do possível, complementar esse material com temas e materiais extras a fim de instigar o interesse dos alunos em sala de aula e pela língua. MC acredita que se as turmas fossem niveladas pelo grau de conhecimento da língua e se trabalhos paralelos pudessem ser feitos com materiais adequados para cada nível, esses alunos poderiam ter mais tempo de contato com o inglês, além de poder oferecer a esses alunos um melhor acompanhamento no 
ensino dessa língua em todas as suas habilidades, visto que as horas de contato com o idioma também aumentaria. Segundo MC, nossa sociedade precisa se conscientizar da necessidade de aprender o inglês, que segundo ela é importante "para a produção, o desenvolvimento e a propagação de capital intelectual, bem como para a interação com outras culturas e povos e ainda para a propagação de nossa própria cultura pelo mundo".

MC termina a entrevista falando sobre suas expectativas para o ensino de inglês no Brasil, ela acredita que os atuais esforços brasileiros com a promoção do programa Idiomas sem Fronteiras e o diagnóstico dos alunos através da prova TOEFL, mostram que o Brasil começa a enxergar o inglês de forma diferente e com uma importância antes nunca dada. MC acredita que futuros investimentos possam ser feitos para uma melhor formação de profissionais e acredita também na possibilidade de repensarem na carga horária destinada ao ensino do inglês dentro do currículo escolar, de forma a termos um ensino fundamental e médio mais consistente.

\section{Crenças da professora de pomerano}

A professora de pomerano será identificada aqui como GK e trabalha há mais de seis anos na escola municipal EMEIEF-Luiz Guilherme Henrique Potratz, e há quase um ano na escola municipal EMEF- em Vila de Jetibá. Ambas as escolas são de ensino fundamental e a professora diz que na primeira escola, a maioria de seus alunos possui o pomerano como língua materna e que na segunda escola a língua materna da maioria é o Português.

GK acredita que uma das maiores dificuldades para o ensino de pomerano em ambas as escolas é a falta de material próprio para o ensino desse idioma. GK explica que todo o material didático é confeccionado e traduzido pelos próprios professores das escolas municipais e alguns materiais extras são oferecidos pela secretaria de educação local, porém, alguns deles infelizmente sofrem com a falta de apoio da atual administração do município visto que o Programa de Educação Escolar Pomerana (PROEPO) parou de ser promovido. Para GK o congelamento do PROEPO representa uma grande perda para o estado tendo em vista o papel do pomerano nessa comunidade. Ainda segundo GK, a grande maioria de seus alunos gosta muito de aprender pomerano e ela acredita que a razão disso é que o aprendizado desse idioma melhora a autoestima e sensação de pertencimento de seus alunos.

Quanto ao tempo das aulas na escola, GK acredita que possa até ser suficiente para aprender pomerano para alunos que se interessam, mas enfatiza que para que esse uso seja 
frequente é preciso mais tempo, para que todas as áreas sejam trabalhadas e que, no caso do pomerano, é necessário mais apoio da administração, disponibilizando formação para os professores e material impresso, tanto para o professor quanto para o aluno haja vista a falta de livros didáticos e cadernos de atividades para que o aluno use diariamente.

\section{Considerações finais}

Os resultados das análises das duas entrevistas apontam que das três escolas em que estas professoras trabalham, existe uma provável maioria de alunos que possuem o português como língua materna em duas delas: o IFES e a EMEF- Vila de Jetibá. O que é diferente, como apontado por GK na escola EMEIEF-Luiz Guilherme Henrique Potratz. Segundo a professora de pomerano, o provável motivo é a localização das escolas em que ela leciona. Na escola EMEIEF-Luiz Guilherme Henrique Potratz, o pomerano é língua materna predominante visto que esta escola se localiza na zona rural, o que não acontece com o IFES nem com a EMEFVila de Jetibá.

Quanto ao material e ao conteúdo a serem ensinados, as professoras acreditam que ambos poderiam ser melhorados. No caso do pomerano, falta material didático pronto para que os alunos usem em sala e nas tarefas de casa. Já no caso do inglês, falta uma melhor divisão dos alunos por níveis e materiais didáticos mais compatíveis com estes níveis. Sobre o conteúdo e o material didático escolhido para o ensino destas línguas, no caso do pomerano, a escolha é feita pelos próprios professores da língua e no caso do inglês pelo currículo escolar. Ambas participantes da pesquisa acreditam que sua prática e o aprendizado da língua por seus alunos poderiam melhorar se houvesse melhor incentivo para a produção de material didático impresso, em pomerano e no caso do inglês, trabalhos paralelos com os alunos melhor nivelados para garantir um melhor aproveitamento do conteúdo.

A análise da fala da professora de pomerano sugere que na visão dela, esta língua é importante para aumentar a autoestima e manter viva a língua, a cultura e a história desse grupo de imigrantes. Por outro lado, a professora faz críticas à importância dada a esse idioma pelo município, visto que não acontecem mais os cursos de formação ministrados pelo PROEPO e a quantidade de material é pequena quando comparada à necessidade de uso em sala de aula e tarefas para casa.

Para o ensino de inglês, a professora entrevistada acredita que a maioria de seus alunos não percebe a importância da aprendizagem de inglês para a vida acadêmica e profissional. Por outro lado, ela acredita que uma das maiores dificuldades para o ensino dessa língua é a falta 
de nivelamento adequado para que as aulas sejam adequadas para cada grupo de alunos dentro de seus níveis de conhecimento da língua.

O ponto comum entre as crenças das duas professoras se relaciona ao tempo semanal em sala de aula para o aprendizado dessas línguas, afirmando que não é suficiente para que seus alunos se tornem competentes em todas as áreas destas línguas, visto que a competência está relacionada com as habilidades oral e escrita dessas línguas, e a falta de material didático adequado, visto que para o pomerano existem poucos recursos escritos e para o inglês existe uma má organização dos alunos quanto a seus níveis e livros adotados especificadamente para cada nível.

Finalmente, ao contrastarmos as crenças dessas professoras com as políticas linguísticas no Brasil vemos que iniciativas governamentais como os programas Ciências sem Fronteiras e Idiomas sem Fronteiras demonstram que há claramente uma política linguística para o ensino de línguas na educação superior, como já mencionado também em outros trabalhos (FINARDI; ORTIZ, 2015; PINHEIRO; FINARDI, 2014; PINHEIRO; FINARDI, 2016). Essa política mostra que o inglês, nesse nível, é visto como uma língua internacional e língua majoritária, em detrimento ao incentivo ao ensino de línguas minoritárias como o pomerano, talvez pelo foco desses programas, qual seja, o de incentivar a mobilidade de brasileiros para o exterior. Assim, concluímos que é necessário revisar políticas linguísticas e de internacionalização a fim de alinhar essas duas necessidades no Brasil, quais sejam, a de promover e reconhecer a cultura e língua local ao mesmo tempo em que se promove a língua global. O desafio para as políticas linguísticas é justamente esse, promover uma cidadania local e global.

\section{REFERÊNCIAS}

ALTENHOFEN, Cléo V. Bases para uma política linguística das línguas minoritárias no Brasil. In: NICOLAIDES, Christine; SILVA, Kleber; TÍLIO, Rogério; ROCHA, Cláudia (Orgs.) Política e Políticas Linguísticas. Campinas: Pontes Editores, p. 93-116, 2013.

BARCELOS, Ana Maria Ferreira. Crenças sobre aprendizagem de línguas, linguística aplicada e ensino de línguas. Linguagem \& Ensino, Pelotas, v. 7, n. 1, p. 123-156, 2004.

BRASIL. Senado Federal. Lei de Diretrizes e Bases da Educação Nacional: no 9394/96. Brasília: 1996.

BRASIL. Secretaria de Educação Fundamental. Parâmetros curriculares nacionais: terceiro e quarto ciclos do ensino fundamental: língua estrangeira. Brasília: MEC/SEF, 1998.

DAY, Kelly. O Ensino de Língua Estrangeira no Brasil: Entre a Escolha Obrigatória e a Obrigatoriedade Voluntária. Revista Escrita Rua Marquês de São Vicente, n. 15, 2012. 
FERRAZ, Aderlande Pereira. O Panorama Linguístico Brasileiro: a coexistência de línguas minoritárias com o Português. Filol. lingüíst. port., n. 9, p. 43-73, 2007.

FINARDI, Kyria Rebeca. The Slaughter of Kachru's Five Sacred Cows in Brazil: Affordances of the Use of English as an International Language. Studies in English Language Teaching, v. 2, p. 401-411, 2014.

FINARDI, Kyria Rebeca. Language Policies and Internationalisation in Brazil: The Role(s) of English as an Additional Language. In: Lydia Sciriha. (Org.). International Perspectives on Bilingualism. 1ed.Newcastle upon Tyne: Cambridge Scholars Publishing, v. 1, p. 79-90, 2016.

FINARDI, Kyria Rebeca. What Brazil can learn from Multilingual Switzerland and its use of English as a Multilingua Franca. Acta Scientiarum (UEM), v. 39, p. 219-228, 2017.

FINARDI, Kyria Rebeca; FRANCA, C. O Inglês na Internacionalização da Produção Científica Brasileira: evidências da subárea de linguagem e linguística. Intersecções (Jundiaí), v. 19, p. 234-250, 2016.

FINARDI, Kyria Rebeca; ORTIZ, R. A. Globalization, Internationalization and Education: What is the Connection?. IJAEDU- International E-Journal of Advances in Education, v. 1, p. 18-25, 2015.

FINARDI, Kyria Rebeca; PORCINO, Maria Carolina. O Papel do Inglês na Formação e na Internacionalização da Educação no Brasil. Revista Horizontes de Linguistica Aplicada, v. 14, p. 109-134, 2015.

FINARDI, Kyria Rebeca; PREBIANCA, Gicele; MOMM, Christiane Fabíola. Tecnologia na Educação: o caso da Internet e do Inglês como Linguagens de Inclusão. Revista Cadernos do IL, vol. 46. p. 193-208, 2013.

FINARDI, Kyria Rebeca; TYLER, Jhamille. The Role of English and Technology in the Internationalization of Education: Insights from the Analysis of MOOCs. In: 7th International Conference on Education and New Learning Technologies, 2015, Barcelona. Edulearn15 Proceedings. Barcelona: IATED, 2015. v. 1. p. 11-18.

GIMENEZ, Telma. A Ausência de Políticas Para o Ensino de Língua Inglesa nos Anos Iniciais de Escolarização no Brasil. In: NICOLAIDES, Christine; SILVA, Kleber.; TÍLIO, Rogério; ROCHA, Cláudia (Orgs.) Política e Políticas Linguísticas. Campinas: Pontes Editores, 2013.

KUSTER, Síntia. Cultura e Língua Pomeranas: um estudo de caso em uma escola do ensino fundamental no município de Santa Maria de Jetibá - Espírito Santo - Brasil. 2015.

MARTINY, Franciele Maria; BORSTEL, Clarisse Nadir Von. As Políticas Linguísticas de Línguas de Imigrantes. Anais do X Encontro do CELSUL - Círculo de Estudos Linguísticos do Sul UNIOESTE - Universidade Estadual do Oeste do Paraná Cascavel-PR | 24 a 26 de outubro de 2012. 
MORELLO, Rosângela. A Cooficialização da Língua Pomerana no Espírito Santo e no Rio Grande do Sul. Livro Leis e Línguas no Brasil: o processo de cooficialização e suas potencialidades. cap.4. p. 43-52. IPOL. 2013.

MORELLO, Rosângela. O Brasil se mostra multilíngue: vários municípios cooficializam suas línguas. Livro Leis e Línguas no Brasil: o processo de cooficialização e suas potencialidades. cap.6. p. 69-78. IPOL. 2013.

MUNICÍPIO DE PANCAS. Lei n. ${ }^{\circ}$ 987/2007, de 27/07/2007. Dispõe sobre a Cooficialização da Língua Pomerana no município de Pancas [ES] e a inclusão da disciplina de Estudo da Língua no Currículo Escolar, nas Escolas da Rede Municipal de Ensino localizadas nas regiões em que predominam a população descendente no Município. Disponível em: http://www.ipol.org.br/imprimir.php?cod=524. Acesso em 8 de maio 2016.

NEVES, Bruna Clemêncio. O Brasil é um país bilíngue: a cooficialização da LIBRAS. In: Livro, Leis e Línguas no Brasil: o processo de cooficialização e suas potencialidades. cap.9. p. 103-118. IPOL. 2013.

OLIVEIRA, Gilvan Müller de. A cooficialização de línguas em nível municipal no Brasil: direitos linguísticos, inclusão e cidadania. In: Livro, Leis e Línguas no Brasil: o processo de cooficialização e suas potencialidades. cap.2. p. 23-30. IPOL. 2013.

OLIVEIRA, Gilvan Müller de. Políticas Linguísticas: uma entrevista com Gilvan Müller de Oliveira. ReVEL, v. 14, n. 26, p. 382-399, 2016.

\section{PERUZZO, Sabrina P. Crenças Sobre o Ensino de Inglês e Pomerano como Línguas} Estrangeiras no Município de Santa Maria de Jetibá - ES. 2014.

PINHEIRO, Livia Melina; FINARDI, Kyria. Políticas Públicas de Internacionalização e o Papel do Inglês: evidências dos programas CsF e IsF. In: II Conel, 2014, Vitória. Anais do II Conel. Vitória: PPGEL, v. 1.p. 76-78, 2014.

PINHEIRO, Livia Melina; FINARDI, Kyria. O papel do inglês nas políticas linguísticas e de internacionalização. In: III Congresso Nacional de Estudos Linguísticos, 2016, Vitoria. Anais III Conel. Vitoria: PPGEL, 2016. v. 1. p. 819-831.

PREBIANCA, Gicele; CARDOSO, Gisele; FINARDI, Kyria. Hibridizando a Educação e o Ensino de Inglês: questões de inclusão e qualidade. Revista do GEL, v. 11, p. 47-70, 2014.

RAJAGOPALAN, Kanavillil. Política linguística: do que é que se trata, afinal? In: NICOLAIDES, Christine; SILVA, Kleber Aparecido; TÍLIO, Rogério; ROCHA, Claudia Hilsdorf (Orgs.) Política e Políticas Linguísticas. Campinas: Pontes Editores, 2013.

SEIFFERT, Ana Paula. Línguas brasileiras de imigração faladas em São Bento do Sul (SC) estratégias para revitalização e manutenção das línguas na localidade. UFSC. 2009. TRESSMANN, Ismael. Bilinguismo no Brasil: O caso da Comunidade Pomerana de Laranja da Terra - ES. Associação de Estudos da Linguagem do Rio de Janeiro (ASSEL-Rio). Universidade Federal do Rio de Janeiro. Rio de Janeiro. 1998. 
TRESSMANN, Ismael. A Co-oficialização da Língua Pomerana. 2009. In: FARESE:

Disponível em: http://www.farese.edu.br/pages/artigos/pdf/ismael/A\%20co-

oficializa\%C3\%A7\%C3\%A3o\%20da\%20L\%20Pomer.pdf. Acesso em 04 de abril. 2016.

\section{Como referenciar este artigo}

PINHEIRO, Lívia Melina; FINARDI, Kyria Rebeca; PORCINO, Maria Carolina. Políticas linguísticas e ensino de línguas minoritárias e majoritárias no Brasil: o caso do pomerano e do inglês como línguas estrangeiras. Rev. EntreLínguas, Araraquara, v. 5, n. 1, p. 121-141, jan./jun. 2019. E-ISSN: 2447-3529. DOI: 10.29051/el.v5i1.12790

Submetido em: $26 / 03 / 2018$

Aprovado em: 12/04/2019

Publicado em: 30/04/2019 


\section{APÊNDICES}

Questionário usado para entrevistar professora de inglês:

1- Qual o seu nome? MC.

2- Qual a escola/município em que você leciona? IFES Centro Serrano - Santa Maria de Jetibá.

3- Qual o língua que você leciona? Inglês.

4- Há quanto tempo você trabalha nesta escola? Há quanto tempo você ensina essa língua? 3 meses. 8 anos.

5- Quais as dificuldades em sua prática docente? Nessa escola, minhas maiores dificuldades têm sido: a pluralidade de níveis de proficiência em uma mesma sala e a falta de interesse de boa parte dos alunos pela língua inglesa.

6- Qual a língua materna da maioria de seus alunos? Português.

7- Que importância você dá ao ensino da língua que você leciona na vida dos seus alunos e nesta comunidade? Como eles são alunos do curso de administração, costumo enfatizar a necessidade de conhecimento da língua para ampliar os estudos e para entrar no mercado de trabalho.

8- Qual a opinião de seus alunos da língua que você leciona? Sinto que a maior parte deles não se sente capaz de aprender o idioma inglês. Muitos não conseguem perceber a importância do inglês para a vida acadêmica e profissional.

9- Você acredita que as aulas na escola sejam suficientes para que o aluno se torne um usuário competente nessa língua? Não. Apesar de termos duas aulas por semana de 50 minutos cada, o tempo e a quantidade de alunos por sala (40 em média) não permitem a prática de todas as habilidades, principalmente, as habilidades oral e auditiva.

10- Como é decidido o conteúdo ministrado nas aulas? Sigo o plano de ensino estabelecido no início do ano letivo. Abordo os conteúdos à medida que o livro didático proposto pela escola os apresenta. Vez ou outra, procuro selecionar conteúdos de interesse dos alunos para tentar instigar o interesse deles pela língua inglesa.

11- O que você acha que deveria melhorar em relação ao ensino e prática dessa língua na escola em que trabalha e na sociedade como um todo? Acredito que na escola em que trabalho poderia desenvolver um projeto paralelo para o ensino de inglês em que pudéssemos ter turmas niveladas com material adequado a cada uma delas. Isso ampliaria as horas de instrução na língua inglesa e possibilitaria um trabalho mais amplo com relação às habilidades na língua inglesa. Na sociedade como um todo, precisamos conscientizar governantes, gestores e cidadãos em geral de que o inglês tem uma relevância primordial para a produção, o desenvolvimento e a propagação de capital intelectual bem como para a interação com outras culturas e povos e ainda para a propagação de nossa própria cultura pelo mundo.

12- Qual sua expectativa para o ensino dessa língua no Brasil em vista dos incentivos do governo? Entendo que os investimentos governamentais em programas como o Idiomas sem Fronteiras e seus esforços em diagnosticar a proficiência dos alunos brasileiros (por meio de aplicação da prova TOEFL) sugerem que as autoridades passaram a enxergar o idioma inglês como nunca antes, dando-lhe a devida importância. Assim, espero que em breve mais investimentos sejam feitos na formação de profisssionais da área e, principalmente, na educação 
básica com relação ao idioma inglês, para que se repense a carga horária incipiente destinada a essa língua e que se proponha um trabalho mais efetivo e consistente da mesma ao longo do ensino fundamental e médio.

\section{Questionário usado para entrevistar a professora de Pomerano:}

1- Qual o seu nome? GK.

2- Qual a escola/município em que você leciona? Escolas municipais. EMEIEF"Luiz Guilherme Henrique Potratz" e EMEF" Vila de Jetibá.

3- Qual o língua que você leciona? Língua Pomerana.

4- Há quanto tempo você trabalha nesta escola? Há quanto tempo você ensina essa língua? EMEIEF"Luiz.G.H.Potratz trabalho a 6 anos agora vai pro $7^{\circ}$ ano,já na EMEF"Vila de Jetibá está sendo meu $1^{\circ}$ ano.

5- Quais as dificuldades em sua prática docente? Falta de material, pois todo o material é confeccionado e traduzido por nós professores. E nos últimos anos falta de apoio da atual administração do município, pois nem formação do PROEPO, que havia não teve mais.

6- Qual a língua materna da maioria de seus alunos? EMEIEF'Luiz.G.H.Potratz é o Pomerano.Já na EMEF Vila de Jetibá e o português .

7- Que importância você dá ao ensino da língua que você leciona na vida dos seus alunos e nesta comunidade? De maior importância, pois, e uma forma de ajudar a manter viva a Língua, cultura e tradição.

8- Qual a opinião de seus alunos da língua que você leciona? Olha. Gostam muito, sempre tem um e outro que questiona, mas são poucos.mas para muitos, acho que melhora ate a auto estima deles.

9- Você acredita que as aulas na escola sejam suficientes para que o aluno se torne um usuário competence nessa língua? Aos que se interresam sim, mas para que seja frequente o uso da Lingua não temos tempo suficiente para trabalhar todas as áreas.

10- Como é decidido o conteúdo ministrado nas aulas? Seguimos uma proposta que foi elaborada por nos professores da Lingua Pomerana e também trabalhamos os projetos que são oferecidos pela secretaria.

11- O que você acha que deveria melhorar em relação ao ensino e prática dessa língua na escola em que trabalha e na sociedade como um todo? Primeiramente mais apoio pela administração, oferecendo formação para os professores, confecção de material impresso didático para o uso do professor e aluno, pois tem muitas atividades elaboradas e jogos, mas, acho que já deveria ter livros didáticos, cadernos de atividade e jogos disponíveis na escola, para o aluno ter acesso diariamente.

12- Qual sua expectativa para o ensino dessa língua no Brasil em vista dos incentivos do governo? Não respondeu. 